\title{
DIVISION XII / COMMISSON 5 / TASK FORCE PRESERVATION AND DIGITIZATION OF PHOTOGRAPHIC PLATES
}

\author{
CHAIR \\ MEMBERS
}

\author{
R. Elizabeth Griffin \\ 88
}

\section{PROCEEDINGS BUSINESS MEETING on 17 August 2006}

During the GA the Task Force for the Preservation and Digitization of Photographic Plates (PDPP) held an open two-session meeting, during which a formal merger between the WG$\mathrm{AC} / \mathrm{CdC}$ (Commission 8) and the TF-PDPP was confirmed. A dominant fraction of the members already belonged to both groups, and the nature of the merger is such that the activities of the WG-AC/CdC are now performed by the TF-PDPP.

It was also agreed to pursue actively a joint European project to digitize collections of direct plates. The project UDAPAC, formed in 2000 at the Royal Observatory Belgium by a consortium of astronomers from nine countries, would become the cradle for the new collaboration, and funding would be sought collectively from the European Union and/or other likely sources.

A short video of the new Harvard scanner, demonstrating the speed with which a new technology plate scanner could operate, convinced the community of the feasibility of digitizing large numbers of plates in a reasonable space of time.

R. Elizabeth Griffin chair of the Task Force 